\title{
Connections between Successful Aging and Mental Health among Older Adults: The Role of Artistic Leisure Activities
}

\author{
Jaewon Lee, M.S.W, PhD ${ }^{1^{*}}$ and Jennifer Allen, M.S.W' \\ ${ }^{1}$ Assistant Professor, Department of Social Welfare, Inha University, South Korea \\ ${ }^{2}$ Doctoral Student, School of Social Work, Michigan State University, USA
}

\section{Successful Aging and Mental Health}

Older adults who have a positive attitude toward their aging are less likely to be exposed to mental illnesses compared to those with a more negative attitude toward their own aging [1]. Achieving a positive outlook toward aging may be achieved by participating in leisure activities, which can reduce depression or anxiety. Given that a sense of isolation may result in mental health problems such as depression or anxiety [2], leisure activities can be an effective way to relieve depressive symptoms caused by disconnection from other people and to encourage older adults to develop a more positive perception toward aging.

The concept of successful aging, which focuses on positive perspectives on one's life, has been defined as life satisfaction, psychological resources such as autonomy and self-esteem, and good physical health [3]. Good health, physical activity, and the absence of depression are primary indicators that influence successful aging. In this context, engagement in productive activities enables older adults to achieve life satisfaction, ultimately leading to decreased depression $[4,5]$.

\section{Artistic Leisure Activities and Mental Health}

Leisure activities have been regarded as one of the best approaches to achieve successful aging and avoid mental health problems in later life. However, previous literature has mainly focused on leisure-time physical activities and has not distinguished between physical leisure activities and artistic leisure activities [6]. Some research has tried to divide leisure activities into organized group activities, informal social activities, and informal individual activities [7]; however, there is little work that concentrates on artistic leisure activities specifically.

Art therapy shares similarities with artistic leisure activities and has proven the effectiveness of art-related activities. Through engagement in artistic activities, older adults can reduce levels of depression by expressing their loss and grief, for example. Participation in art therapy among the elderly allows them to improve their mental health as well as chronic health conditions [8]. In addition, art therapy enables older adults to formulate their thoughts and feelings and encourage those with cognitive impairments to express their emo- tions in a nonverbal communicative way, and these effects can result in improved psychological health [9]. Given that depression is a factor for the elderly to commit suicide and is regarded as an abnormal phenomenon of aging, it is important to engage in activities that may reduce depression among older adults, such as artistic leisure activities.

\section{Conclusion}

It is critical to provide distinctions among leisure activities by focusing on artistic leisure activities in particular. The definition of artistic leisure activities refers to involvement in music or art, such as by visiting an art museum or gallery, learning a musical instrument, or making art or craft objects, rather than physical exercises. As older adults' physical abilities often reduce as they age, participation in artistic leisure activities, which do not require physical activities and have beneficial effects on mental health, should be encouraged to older adults to help them achieve successful aging, thereby making it possible to maintain a good quality of life and mental health in later life.

\section{References}

1. Sarkisian CA, Hays RD, Mangione CM (2002) Do older adults expect to age successfully? The association between expectations regarding aging and beliefs regarding healthcare seeking among older adults. J Am Geriatr Soc 50: 1837-1843.

2. Hughes ME, Waite L, Hawkley LC, et al. (2004) A short scale for measuring loneliness in large surveys: Results from two population-based studies. Res Aging 26: 655-672.

3. Bowling A (2007) Aspirations for older age in the 21st century: What is successful aging? Int J Aging Hum Dev 64: 263-297.

*Corresponding author: Jaewon Lee, M.S.W, PhD, Assistant Professor, Department of Social Welfare, Inha University, 100 Inha-ro, Michuhol-gu, Incheon 22212, South Korea, Tel: 82-32860-9324, Fax: 82-32-863-3022

Accepted: April 27, 2021

Published online: April 29, 2021

Citation: Lee J, Allen J (2021) Connections between Successful Aging and Mental Health among Older Adults: The Role of Artistic Leisure Activities. J Depress Anxiety Disord 3(1):80-81 
4. Benyamini $Y$, Lomranz $J(2004)$ The relationship of activity restriction and replacement with depressive symptoms among older adults. Psychol Aging 19: 362-366.

5. Howie L (2007) Health and well-being through occupation in later life. Lessons on aging from three nations. In: S Carmel, $C$ Morse, $\mathrm{F}$ Torres-Gil, The art of aging well. Baywood Publishing Co, Amityville, NY, US, 19-28.

6. Dafna M, Carmen C, Kamalesh V, et al. (2012) How diverse was the leisure time physical activity of older Australians over the past decade? J Sci Med Sport 15: 213-219.
7. Van Naarden Braun K, Yeargin-Allsopp M, Lollar D (2006) Factors associated with leisure activity among young adults with developmental disabilities. Res Dev Disabil 27: 567-583.

8. McCaffrey $R$ (2007) The effect of healing gardens and art therapy on older adults with mild to moderate depression. Holist Nurs Pract 21: 79-84.

9. Johnson CM, Sullivan-Marx EM (2006) Art therapy: Using the creative process for healing and hope among African American older adults. Geriatr Nurs 27: 309-316. 